\title{
DOCUMENTOS DE COMUNICACIÓN EN LOS MANUALES DE IDENTIDAD CORPORATIVA DE LA ADMINISTRACIÓN PÚBLICA ESPAÑOLA
}

\author{
María-del-Carmen Rodríguez-López
}

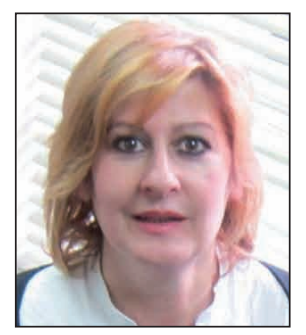

María-del-Carmen Rodríguez-López, doctora por la Universidad de León, es profesora titular del Área de Biblioteconomía y Documentación de la misma universidad. Imparte docencia en las diplomaturas en biblioteconomía y documentación y en gestión y administración pública, como profesora responsable de las asignaturas de archivística y archivos administrativos. Entre sus líneas de investigación se encuentran: actas municipales, ponderación del valor económico de la gestión del servicio de archivo de historias clínicas, sistemas de gestión del documento de archivo y, en este último año ha emprendido la organización del fondo de la Facultad de Educación de la Universidad de León y su aprovechamiento como recurso educativo.

Universidad de León, Facultad de Filosofía y Letras Campus de Vegazana, s/n. 24071 León, España mcrodl@unileon.es

\section{Resumen}

Los manuales de identidad corporativa empleados por la Administración Pública española en el ámbito estatal, autonómico o local recogen la normativa de cómo mostrar la respectiva imagen institucional a sus usuarios. Tal imagen no es un concepto estático, sino que evoluciona según la sociedad. En este trabajo se definen logotipo, tipografía, formato y materiales impresos, así como los tres documentos más corrientes de transmisión de actos administrativos: nota interior, oficio y carta, que forman parte de la papelería.

\section{Palabras clave}

Manuales de identidad corporativa, Identidad visual, Documento administrativo, Documentos de transmisión, Estructura diplomática.

Title: Communication style standards in the corporate identity manuals of the Spanish Public Administration

\begin{abstract}
Corporate identity manuals used by Spanish public administrations at the state, regional or local level set the standards for the respective corporate image that is displayed to the public. Corporate image is not a static concept, but evolves with society. Concepts such as logo, typography, format and print materials are defined, as well as the stationery for the three most common communications of administrative action: internal memo, inter-office document, and letter.
\end{abstract}

\section{Keywords}

Corporate identity manuals, Visual identity, Administrative documents, Transmittal documents, Diplomatic structure.

Rodríguez-López, María-del-Carmen. “Documentos de comunicación en los manuales de identidad corporativa de la Administración Pública española”. El profesional de la información, 2011, marzo-abril, v. 20, n. 2, pp. 281-289.

DOI: 10.3145/epi.2011.may.06

\section{Introducción}

"Una imagen vale más que mil palabras", el conocido eslogan publicitario, también puede aplicarse a los manuales de identidad corporativa, que constituyen la base de las relaciones públicas de cada institución. Dada su importancia es frecuente que su elaboración se encargue a empresas especializadas.

En la sociedad actual, tan competitiva, las organizaciones crean marcas, logotipos e imagotipos amigables y fácilmente identificables que las distingan de las demás, intentando con ellos transmitir una imagen de calidad, de confianza y de transparencia. Por su lado, los clientes, usuarios o administrados prefieren relacionarse con instituciones reconocidas por su buena imagen.

\section{Metodología}

Se han consultado varios manuales de identidad corporativa

Artículo recibido el 22-01-11

Aceptación definitiva: 02-03-11 
en la Red, y se han realizado búsquedas bibliográficas y de la legislación que afecta al tema.

La búsqueda más pormenorizada se ha hecho sobre las administraciones públicas: la Administración General del Estado (AGE), y en particular la Dirección General de Tráfico (DGT), así como entre las comunidades autónomas: Junta de Andalucía, Gobierno de Canarias, Generalitat de Catalunya, Comunidad de Madrid, Región de Murcia, Gobierno de Aragón, Gobierno Vasco y Junta de Castilla y León. En este último caso se consultó también el manual de la Gerencia Regional de Salud (Sanidad de Castilla y León, Sacyl).

http://www.060.es/060/appmanager/portal/desktop/pa ge/websPublicas_menuGeneral

http://www.dgt.es/portal/es/prensa_campanas/manual_ imagen_corporativa

http://www.juntadeandalucia.es/presidencia/impe/presi dencia/navegacion?idSeccion $=e a 0 b 1 b 4 a-b 7 d f-11 d e-983 c-$ $00127968 a 9 b a$

http://www.gobiernodecanarias.org/identidadgrafica

http://www.gencat.cat/piv

http://www.madrid.org/cs/Satellite?c=Page \&cid=1109265 $463144 \&$ language $=$ es \& pagename $=$ ComunidadMadrid\% $2 \mathrm{~F}$ Estructura\&pid $=1109265463020 \& s c=0$

http://www.carm.es/web/pagina?IDCONTENIDO=127\&IDTI $P O=100 \& R A S T R O=c \$ m 22660$

http://www.aragon.es/Temas/ComunicacionCorporativa

http://www.osanet.euskadi.net/r85-20337/es/contenidos/ informacion/identidad_corporativa/es_5611/adjuntos/ MANUAL_ID_CORPORATIVA.PDF

http://www.jcyl.es/web/jcyl/Gobierno/es/Plantilla100/ 1164279270965/_/__

http://www.salud.jcyl.es/sanidad/cm/institucion/tkContent ?idContent $=18401$ \&locale $=e s \_E S \&$ textOnly=false

Dentro de la administración local han sido consultados los manuales de la Diputación de Badajoz, la Diputación de León, y el Ayuntamiento de San Sebastián de los Reyes

http://www.dip-badajoz.es/diputacion/identidad_corpora tiva/index.php

http://www.dipuleon.es/frontdipuleon/frontDipuleonAc tion. . ? action=viewCategory\&id=1208921

http://www.ssreyes.org/acces/recursos/doc/Nuestra_ciu dad/Imagen_corporativa/218563158_272200993450.pdf

También se han tenido en cuenta los manuales de las universidades de León, Zaragoza, Sevilla, Cádiz, Santiago, VaIladolid y Pablo de Olavide:

http://www.unileon.es/info_gral/imagen.htm

http://www.unizar.es/sg/doc/3.manual_once_.pdf

http://www.us.es/acerca/comunicacion/imagen/

http://www.uca.es/web/organizacion/equipo_gobierno/ dgcri/visual/elementos/manual_id_visual

http://www.usc.es/es/info_xeral/imaxeusc
http://www.psc.uva.es/logos_uva/pdf/UVa\%20MANUAL \%2OIDENTIDAD.pdf

http://www.upo.es/general/n_servicios/generales/prensa/ manual_upo/manual/manualupo.htm

Por último, se han analizado los manuales de algunas empresas públicas: Renfe, Telefónica y AENA (Aeropuertos Españoles y Navegación Aérea).

http://www.renfe.com/empresa/comunicacion/marca/index.html

http://www.telefonica.com/es/telefonica_brands/at_identidad_marcas_telefonica.shtml

http://www.aena.es/csee/ccurl/948/359/manual_aena.pdf

\section{Diferentes nombres de los manuales}

Parece no haber acuerdo en la denominación: manual de imagen corporativa, manual de identidad corporativa, manual de imagen institucional, manual de identidad visual... La Administración Central y Autonómica se decantan indistintamente por los dos primeros, pero las universidades españolas tienen una marcada preferencia por la denominación manual de identidad visual. Los términos "identidad" e "imagen" son empleados de forma parecida, cosa que puede deberse a la consideración inicial de "identidad corporativa" como sinónimo de logotipo, estilo corporativo y otras formas de simbolismo utilizadas por una entidad (Fernández-Souto, p. 2).

Los manuales son el instrumento para la creación de una imagen con la que una entidad pretende proyectarse

Cees Van-Riel (1997, p. 36) indica que la identidad corporativa es la "auto presentación de la empresa estratégicamente planificada y operativamente aplicada, basándose en una imagen deseada". Los manuales, se autodenominen de imagen o de identidad, son un instrumento al servicio de la creación de una imagen con la que una entidad pretende proyectarse. La Administración del Estado habla ya de imagen promocional ${ }^{1}$. Se trata de elaborar la imagen que cada entidad quiere que de ella tengan sus usuarios, sabiendo que la imagen no es un concepto estático, sino que se adapta a los cambios experimentados en la sociedad donde se desenvuelve y es sensible a las modas ${ }^{2}$. Así la imagen corporativa se convierte en la percepción que tiene un determinado público de una institución, la personalidad corporativa emana de una institución y la imagen deriva de la evocación que los individuos realizan de la misma a partir de la interacción de sus experiencias, impresiones, creencias, sentimientos y conocimientos sobre ella (Fernández-Souto, p. 2). Se trata de una imagen mental ligada a una corporación y a lo que ella representa.

El Manual de identidad corporativa es el conjunto de normas que regulan el uso y aplicación de la identidad en el plano del diseño, reunidas en un documento en el que se establecen las líneas maestras de la imagen de la institución. Se definen las normas que se deben seguir para imprimir el 
logotipo en los diferentes soportes internos y externos de la institución, poniendo especial cuidado en aquellos que llegan al dominio público³. Varían en su estructura pero no tanto en los contenidos básicos. Oscilan entre tres capítulos, los más breves (Diputación de Badajoz, por ejemplo), y los nueve capítulos del Manual de la Administración General del Estado ${ }^{4}$, pero los contenidos son similares:

- normas básicas de elaboración de la identidad corporativa;

- signos para utilizar en los medios de comunicación: promoción, publicidad, relaciones públicas, etc.;

- tipografía y elementos de aplicación a las comunicaciones de la entidad en la papelería: papel de carta, sobres, carpetas, facturas, albaranes, tarjetas de visita, invitaciones, blocs de notas, etc.;

- normativa de señalización interna y externa (señalética) carteles, indicadores, etc.;

- signos que se imprimirán en el parque móvil: camiones, furgonetas de reparto, etc.;

- signos para colocar en equipamientos y uniformes del personal.

\section{Documentos de transmisión. Papelería de la Administración española}

Este apartado se dedica a la "tipografía y elementos de aplicación a las comunicaciones de la entidad a través de papelería". Con esta denominación la AGE se refiere a un grupo de los documentos administrativos de transmisión como material impreso, y por simpatía también lo hace un buen grupo de administraciones autonómicas y locales. O sea, se asimilan a papelería.

Sin embargo hay diferencias sustanciales entre los manuales de estas administraciones. La local y, en general, las universidades, suelen incluir únicamente la carta en el apartado papelería, aunque también pueden aparecer la comunicación interna y el oficio. La Universidad de Zaragoza, por ejemplo, incluye el oficio y la carta "académica". En definitiva los usos no son uniformes en ningún caso.

La AGE se propone el establecimiento de una imagen institucional que "lleve aparejadas además la normalización y racionalización del material utilizado por la Administración en su actuación, prestando especial atención a la necesidad de articular un modelo de actividad administrativa eficiente, ágil, transparente y respetuosa con los ciudadanos. En este sentido, los documentos e impresos de la Administración tienen especial importancia en cuanto que constituyen el principal instrumento en las relaciones entre los ciudadanos y la organización administrativa" (Real decreto 1465/1999). No debería mezclarse en un mismo concepto como "papelería" tipos tan diversos como: cartas, informes, sobres, tarjetas de visita, tarjetones, saludas, y otros impresos como: inscripción en registros de agentes de publicidad, nota de llamadas, carpetas (entre ellas la de expediente), bloc de notas, comunicación interior, hoja de fax, invitación, diplomas, convenios, tarjetas de invitación personal y de visitantes, otras tarjetas, sellos, bolsas, papel, etiquetas y cintas de embalaje, elementos que se suelen encontrar en este apartado de los manuales ${ }^{5}$.

\section{Documentos administrativos de transmisión. Material impreso}

Los documentos de transmisión cumplen con la función de comunicar un acto administrativo a ciudadanos o a entidades privadas, y también a órganos o unidades administrativas. Entre los primeros se encuentran la notificación, la publicación y la comunicación (Sánchez-Prieto, 1995, p. 206).

\section{Notificación}

Es el trámite por el que el órgano competente comunica al interesado una resolución o acuerdo. Por prescripción legal (Art. 58 Ley 4/1999) el documento de notificación incluye, inserto en su tenor, el documento de decisión que contiene el acto transmitido, indicando si agota o no la vía administrativa y los recursos que proceden, aparte de otros datos. Esta obligación de transcribir la decisión se sustituye por adjuntarla a la notificación, lo que ha hecho que se unifiquen en un mismo soporte material y bajo una misma suscripción.

\section{Publicación}

Es la notificación por tablón de anuncios o diario oficial, reforzada o no con la difusión simultánea por otros medios (radio, prensa, etc.). A veces adquiere formas peculiares como el edicto (documento cuya finalidad es dar difusión de un determinado hecho, cuando lo que se desea notificar no tiene un interesado conocido, o cuando el asunto de que trata se quiere hacer público), pero por lo general no se atiene a un modelo, salvo en la obligación de contener el texto íntegro de la resolución, la indicación de si es o no definitiva en vía administrativa y los recursos que proceden, órgano ante el que se presenta y plazo de interposición. La publicación no se refleja en un documento con especiales singularidades, ya que es una actividad de inserción de otros documentos: los de decisión y las notificaciones. Se regula en los Arts. 59, 60 y 61 de la Ley 30/1992.

\section{Comunicación}

A diferencia de los dos anteriores, es el documento destinado a poner en conocimiento de los ciudadanos hechos o circunstancias de un procedimiento de la administración, como el plazo máximo de duración de los procedimientos (o su suspensión o reanudación) y de los efectos del silencio administrativo, pero no transmite a los ciudadanos decisiones administrativas como los dos tipos anteriores (MAP, 2003, p. 74).

Los tres tipos documentales de transmisión básicos: oficio, nota interior y carta se encuentran dentro del material impreso, incluso se habla a veces de papelería comercial. El Manual de documentos administrativos no incide su estructura más que en unos breves ejemplos (MAP, 2003, p. 74).

\section{Asimilar documentos de transmisión con soportes de impresión conlleva un riesgo}

\section{Notas, oficios y cartas}

Los documentos administrativos de transmisión son documentos públicos por los que las administraciones públicas 
se ponen en contacto entre sí o con los administrados para transmitir hechos o actos.

Los autores y destinatarios pueden ser:

- órganos pertenecientes a una misma organización;

- órganos o unidades pertenecientes a distintas organizaciones administrativas.

Los destinatarios pueden ser:

- ciudadanos

- entidades privadas

\begin{tabular}{|c|c|}
\hline \multicolumn{2}{|r|}{$\begin{array}{l}\text { Documentos de transmisión según las relaciones entre } \\
\text { emisor y receptor }\end{array}$} \\
\hline Internos & $\begin{array}{l}\text { Emisor y receptor pertenecen a una misma organización } \\
\text { administrativa }\end{array}$ \\
\hline Externos & $\begin{array}{l}\text { El receptor es: } \\
\text { - Un ciudadano } \\
\text { - Una entidad privada } \\
\text { - Un órgano o unidad perteneciente a una administración } \\
\text { pública diferente de aquella en la que está integrado el } \\
\text { emisor }\end{array}$ \\
\hline
\end{tabular}

Tabla 1. Clasificación de los documentos de transmisión, basada en el Manual de documentos administrativos, pp. 67

Tipos de documentos de transmisión cuando los destinatarios son ciudadanos o entidades privadas:

- notificación y acreditación de la notificación

- publicación

- comunicación

Tipos de documentos de transmisión en función de su diseño formal:

- nota interior

- oficio

- carta

Base normativa:

- Real decreto 1465/1999, de 17 de septiembre, por el que se establecen criterios de imagen institucional y se regula la producción documental y el material impreso de la AGE (BOE n. 320, de 25 de septiembre de 1999).

“Capítulo I. Ámbito de aplicación:

Los órganos de la AGE, los organismos autónomos dependientes de ella y los servicios comunes y entidades gestoras de la Seguridad Social se ajustarán a lo previsto en el presente Real decreto y en sus disposiciones de desarrollo en lo concerniente a: emisión, elaboración o utilización de documentos, modelos normalizados y material impreso.

Cap. IV. Material impreso: el material impreso normalizado para su utilización en comunicaciones de tipo general se clasificará en: oficios, notas interiores y cartas".

- Orden de 27 de septiembre de 1999 por la que se aprueba el Manual de imagen institucional de la $A G E$ y se dictan normas de desarrollo del Real decreto 1465/1999, por el que se establecen criterios de imagen institucional y se regula la producción documental y el material impreso de la AGE (BOE n. 232, de 28 de septiembre de 1999).
“Disposición final: Las normas incluidas en los apartados 4, 5, 6, 7 y 8 tienen carácter de recomendación, sin perjuicio del necesario cumplimiento de las regulaciones contenidas en el Real decreto 1465/1999".

\begin{tabular}{|l|l|l|}
\hline \multicolumn{2}{|c|}{$\begin{array}{r}\text { Documentos de transmisión en función de la condición } \\
\text { del destinatario y diseño formal }\end{array}$} \\
\hline \multirow{2}{*}{$\begin{array}{l}\text { Destinatario públi- } \\
\text { co; en función de } \\
\text { su diseño formal y } \\
\text { dentro del material } \\
\text { impreso la Adminis- } \\
\text { tración usa: }\end{array}$} & Oficio & $\begin{array}{l}\text { Dirigida a órganos o unida- } \\
\text { des administrativas }\end{array}$ \\
\cline { 2 - 3 } & Carta & $\begin{array}{l}\text { Dirigido a órganos o unida- } \\
\text { des administrativas y a ciu- } \\
\text { dadanos }\end{array}$ \\
\hline \multirow{2}{*}{$\begin{array}{l}\text { Documentos dirigi- } \\
\text { dos a ciudadanos o } \\
\text { entidades privadas }\end{array}$} & Publicación & $\begin{array}{l}\text { Comunicación personal o } \\
\text { protocolaria }\end{array}$ \\
\cline { 2 - 3 } & \multicolumn{2}{|c|}{$\begin{array}{l}\text { De actos administrativos de- } \\
\text { dinitivos o de trámite (acuer- } \\
\text { dosoluciones) }\end{array}$} \\
\cline { 2 - 3 } & Comunicación & $\begin{array}{l}\text { De hechos o circunstancias } \\
\text { de un procedimiento de la } \\
\text { Administración }\end{array}$ \\
\hline
\end{tabular}

Tabla 2. Clasificación de los documentos de transmisión, basada en el Manual de documentos administrativos, pp. 68

\section{Estructura diplomática ${ }^{6}$}

En general, el documento administrativo presenta la siguiente estructura:

- signos y marcas de expedición: nombre, escudo y anagrama de la organización;

- protocolo inicial: datos de identificación;

- texto o cuerpo: contenido del documento;

- escatocolo ${ }^{7}$ o protocolo final: data tópica (lugar) y crónica (fecha); firma.

El elemento identificativo del documento administrativo es el membrete. Es un signo externo no validador utilizado por la mayoría de los organismos oficiales, situado en el margen superior del documento, que indica la procedencia. En él suele figurar el nombre de la identidad y una figura igual o semejante a la del sello (Sánchez-Prieto, 1995, p. 200) compuesto por una parte textual o logotipo y una parte gráfica o imagotipo.

Ambos suelen colocarse juntos como imagen institucional. Por lo general uno encima del otro, aunque también pueden disponerse sueltos ${ }^{8}$. El logotipo contiene los datos más sucintos posible del productor o emisor del documento ${ }^{9}$. Igualmente, figura el nombre y los apellidos del titular del puesto de trabajo o la jefatura de la unidad si es alto cargo. Fuera del membrete figuran el nombre y los apellidos de los responsables directos de los documentos o modelos impresos.

El imagotipo habitual es el escudo institucional que representa a cada administración que produce los documentos. Son iconos o imágenes que atribuyen la autoría de un documento a golpe de vista. Las instituciones diseñan su escudo, que suele ser una imagen muy similar al sello, no viceversa, elemento validador por excelencia. El imagotipo primordial de la administración pública española es el escudo nacional admitiéndose tanto en su aspecto heráldico habitual (en blanco y negro o en color), como con su aspecto simplificado o realzado según la solemnidad del documento o la entidad del emisor. 
Este elemento visual se empieza a usar, finalizado el Antiguo Régimen ${ }^{10}$, en determinados documentos de comunicación oficial, alcanzando en estos momentos una importancia destacada en la estructura diplomática del documento.

\section{No deberían mezclarse en el concepto} papelería tipos tan diversos como: cartas, informes, sobres, tarjetas de visita, tarjetones, saludas...

\section{Nota interior}

Se utiliza para la comunicación entre órganos inferiores o unidades administrativas de un mismo órgano superior. Se distingue a simple vista por la ausencia de membrete, si bien tiene como marca de expedición las siglas del redactor y el mecanógrafo separadas por una barra, o cualquier otra referencia abreviada que identifique la oficina emisora. Estos documentos tienen un contenido que pierde vigencia casi inmediatamente, suelen ser cuestiones particulares de la administración. Es muy similar al oficio. La nota que les diferencia es el ámbito de actuación.

\begin{tabular}{|l|l|}
\hline \multicolumn{1}{|c|}{ [sin logotipo] } \\
\hline \multirow{3}{*}{ Protocolo } & $\begin{array}{l}\text { Data tópica y crónica } \\
\text { Título, reducido a la expresión "Nota interior" } \\
\text { Autor, tras la expresión "De" } \\
\text { Destinatario, tras la expresión "A" } \\
\text { Asunto de forma sucinta }\end{array}$ \\
\hline Texto & Mensaje a transmitir: de forma clara y ordenada \\
\hline Escatocolo & $\begin{array}{l}\text { Suscripción. Es suficiente con la rúbrica o acredita- } \\
\text { ción parecida }\end{array}$ \\
\hline
\end{tabular}

Tabla 3. Estructura diplomática de la nota interior

A pesar de lo dicho, cada vez con mayor frecuencia las entidades optan por dar a la nota interior el formato de la comunicación en general, es decir que se prevé el espacio para el membrete. En el diseño de estos documentos se establece con claridad la ubicación del logotipo del centro, su formato, tipo de papel, gramaje y color. Del mismo modo, queda fijada la tipografía con la que se escriben los órganos de la administración o institución, situados debajo del identificador, la tipografía recomendada para el texto de la nota interior y la idónea para escribir el título del documento, en un tamaño superior a las demás ${ }^{11}$. Aunque no es necesario, en varios manuales aparece el acuse de recepción de estos documentos.

Características formales de redacción:

- Data tópica y crónica: especificación del lugar y fecha en que se realiza la nota interior.

- Autor o remitente: nombre y apellidos de la persona que envía la nota y cargo que ocupa.

- Destinatario: nombre y apellidos de la persona a la que va dirigida la nota interior y cargo que ocupa.

- N/ref. ("Nuestra referencia”, es la marca de la oficina emisora. Se trata de un carácter externo no validador, como el título y el asunto): indicar mediante letras o números la referencia de procedencia proporcionando las siglas del redactor y el mecanógrafo separadas por una barra, o cualquier otra referencia abreviada que identifique la oficina emisora.

- S/ref. ("Su referencia"): indicar mediante letras o números la referencia de procedencia. Si el documento se envía por primera vez, la unidad emisora consignará la referencia y cuando sea contestado, la unidad receptora deberá consignar tanto la referencia del documento al que se contesta como la del documento al que responde.

- Asunto: se expondrá de forma clara y breve lo que se desee comunicar.

- Firma: rúbrica (no necesita más indicaciones puesto que el remitente se ha identificado ya).

\section{Oficio}

Es un documento administrativo que un organismo oficial emite, integrado en la tramitación de un procedimiento administrativo. Quizás la definición más adecuada la proporcionó Sierra-Valenti: "es una carta entre dos autoridades, escrita con carácter oficial, de donde se deriva su nombre. Diplomáticamente, el oficio difiere de las cartas particulares por ir provisto de membrete, oblea o falso membrete a mano y por dejar de margen la mitad del papel, al efecto de facilitar la redacción de diligencias y notas de informe". Tiene membrete, marca de expedición con la identificación del rogatario (redactor/mecanógrafo) o cualquier otra referencia abreviada que identifique la oficina emisora y, si se conoce, la receptora (Sierra-Valenti, 1979). Se usa entre órganos o unidades administrativas pertenecientes a distintas administraciones públicas, entidades o departamentos y órganos superiores.

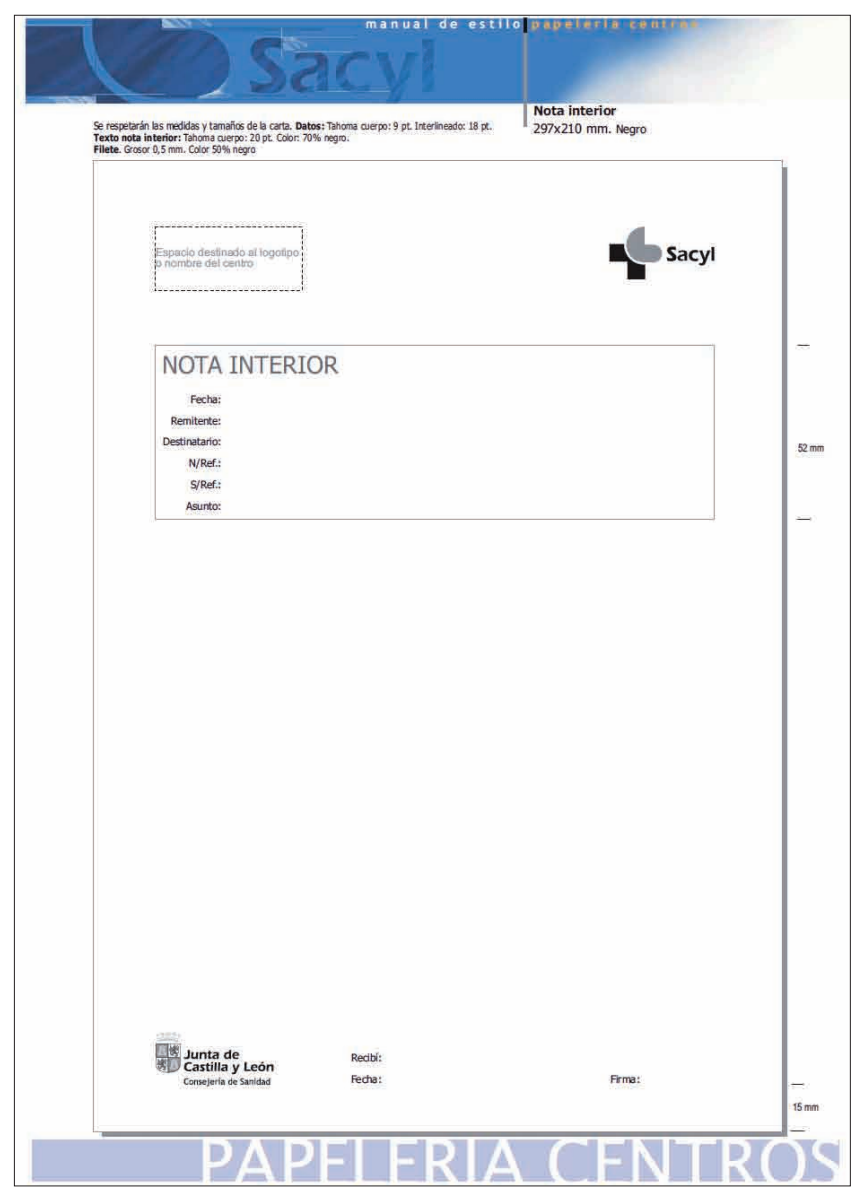

Figura 1. Nota interior. Manual de estilo del Sacyl 


\begin{tabular}{|l|l|}
\hline \multicolumn{2}{|c|}{ Logotipo del organismo de origen del oficio } \\
\hline Protocolo & $\begin{array}{l}\text { Data tópica y crónica completa encabezando el oficio } \\
\text { Asunto de forma sucinta } \\
\text { [O viceversa: el asunto y la data] }\end{array}$ \\
\hline Texto & $\begin{array}{l}\text { Mensaje a transmitir: de forma clara y ordenada. El } \\
\text { cuerpo del oficio ha de tratar de un solo tema, ya que } \\
\text { es una comunicación oficial que hace referencia a un } \\
\text { procedimiento administrativo determinado }\end{array}$ \\
\hline Escatocolo & $\begin{array}{l}\text { Data tópica y crónica } \\
\text { Suscripción: con antefirma, delegación, en su caso, fir- } \\
\text { ma y rúbrica pisada por el sello y firmado con nombre y } \\
\text { apellidos y cualquier otra acreditación equivalente. En } \\
\text { el oficio lo que es importante es el cargo y no el nom- } \\
\text { bre concreto de la persona que lo ocupa. } \\
\text { Dirección: al pie del documento, conteniendo los datos } \\
\text { del destinatario, el cargo o puesto que desempeña, con } \\
\text { indicación de la unidad o dependencia y el órgano o } \\
\text { departamento en el que trabaja (en esto coincide con } \\
\text { la instancia) }\end{array}$ \\
\hline
\end{tabular}

Tabla 4. Estructura diplomática del oficio

\section{Características formales de redacción:}

- El logotipo del organismo de origen del oficio y la dirección completa normalmente están impresos en la cabecera izquierda del papel. También, a veces, en la parte superior derecha tiene unas casillas para poner el lugar, fecha, n. de expediente o extracto del asunto y la dirección.

- Asunto: se ha de especificar brevemente el tema de que trata el documento (una o dos frases). Conviene destacar el título de este apartado (negrita, subrayado, etc.).

- Cuerpo del oficio: con un lenguaje impersonal y neutro, de acuerdo con la naturaleza del documento. Tampoco se han de emplear fórmulas de salutación. A diferencia de la carta, ha de tratar de un solo tema, ya que es una comunicación oficial que hace referencia a un procedimiento administrativo determinado. El texto debe distribuirse en párrafos, entre los que se dejará un espacio destacando en letra cursiva aquellas referencias normativas o bibliográficas citadas.

- Lugar y fecha.

- Suscripción: el carácter oficial de este documento hace que el orden de los elementos de la firma sea diferente del de la carta: antefirma, delegación, en su caso, firma y rúbrica pisada por el sello y firmado con nombre y apellidos y cualquier otra acreditación equivalente. En el oficio lo que importa es el cargo frente al nombre concreto de la persona que lo ocupa. El nombre, también se ha de consignar si se dirige a un particular.

- Datos del destinatario: La Orden del Ministerio de Presidencia, de 7 de julio de 1986, especifica: "respecto al destinatario, que figurará al pie del escrito figurarán los datos del cargo o puesto que desempeña, con indicación de la unidad o dependencia y el órgano o departamento en el que trabaja". En caso de que el documento circule entre las administraciones se ha de consignar, además del cargo y el organismo receptor, la dirección postal; si el documento va dirigido a un particular, se ha de consignar el nombre completo y la dirección completa del destinatario. Si se trata de un órgano administrativo se dirigirá al cargo que desempeña la persona (posibilidad de usar "Sr.").

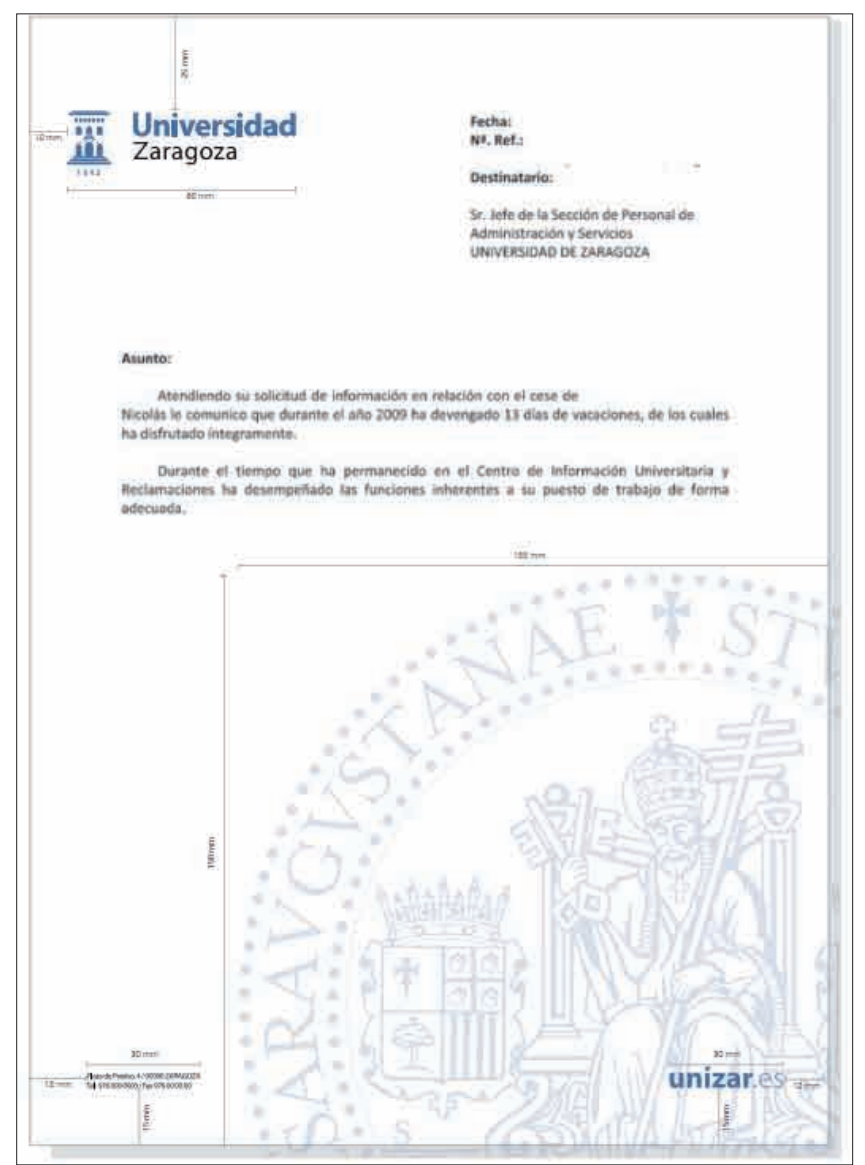

Figura 2. Oficio. Manual de identidad corporativa de la Universidad de Zaragoza, p. 82

Características comunes de la nota interior y el oficio (MAP, 1003, pp. 88-90)

- Contenido estrictamente administrativo y oficial, tono formal, neutro y objetivo.

- Se centran en la actuación administrativa.

- Los principios que rigen su redacción son: redacción concisa y formal, claridad y brevedad, rigor en los términos empleados y estructuración en párrafos breves y separados.

- Título, indicando el tipo de documento: oficio o nota interior.

- En ambos, la referencia a las personas y cargos se hará: sin utilizar tratamientos (en el caso de personas), o con la denominación orgánica en el caso de los cargos (ej. "Ministro de Ciencia y Tecnología").

- Referencias: en ambos se deben consignar los códigos de letras o números que permiten conocer las referencias de procedencia o destino.

- Fecha del documento.

- Asunto: en ambos casos de forma sintética el objeto al que se refiera la comunicación.

- Destinatario: se indica en el encabezamiento el nombre y apellidos, así como el cargo del destinatario de los documentos.

- La identificación funcional y nominativa del emisor debe aparecer en la parte final del documento.

\section{Carta}

Los particulares pueden dirigirse a la administración mediante cartas, siempre que las normas de procedimiento administra- 
tivo no exijan que se adopte una forma especial. Son comunicaciones escritas de carácter interpersonal, de contenido general y no previsto en la tramitación de un procedimiento administrativo. Estos documentos cumplen también funciones de comunicación.

\begin{tabular}{|l|l|}
\hline \multicolumn{2}{|c|}{ Logotipo del organismo de origen de la carta } \\
\hline \multirow{5}{*}{ Protocolo } & $\begin{array}{l}\text { Dirección protocolaria: nombre y apellidos, seguidos, } \\
\text { en su caso, del cargo o puesto de trabajo del destina- } \\
\text { tario. La dirección ha de ser lo más completa posible, } \\
\text { incluyendo el código postal. Se sitúa arriba y a la dere- } \\
\text { cha de la carta. } \\
\text { Data tópica y crónica, o sólo crónica, extensa o abrevia- } \\
\text { da (margen superior izquierdo) } \\
\text { Segunda dirección coloquial o cortés: "Señores" (es la } \\
\text { dirección más recomendable), "Estimado colega” "Esti- } \\
\text { mado Sr." o similares. Si la carta no se dirige a una per- } \\
\text { sona sino a la entidad, y a la atención de una persona } \\
\text { concreta, el saludo deberá hacerse en plural: "Estima- } \\
\text { dos señores" (seguido de :) }\end{array}$ \\
\hline Texto & $\begin{array}{l}\text { Parte central del documento destinada a tratar diver- } \\
\text { sos temas y con un contenido flexible }\end{array}$ \\
\hline Escatocolo & $\begin{array}{l}\text { Fórmulas de cortesía en la despedida: "Atentamente”, } \\
\text { "Cordialmente", “Un saludo cordial” (seguido por "','). } \\
\text { Suscripción o equivalente, con los elementos: antefir- } \\
\text { ma, rúbrica y reconocimiento de firma } \\
\text { Posibilidad de usar el elemento postdata (P.D.) para in- } \\
\text { dicar al pie de página informaciones adicionales }\end{array}$ \\
\hline
\end{tabular}

Tabla 5. Estructura diplomática de la carta

\section{Características formales de redacción:}

- No existe un formulario, normalmente la información impresa se limitará al conjunto logotipo-símbolo-denominación; el resto de la información será completada por cada usuario. En la papelería de prestigio (reservada a los órganos de gobierno más elevados de la institución, sea esta del tipo que sea), el nombre, cargo y dirección sí pueden ser realizados en imprenta.

- Las cartas han de ser claras, concretas y correctas.

- Las ideas, datos o información a transmitir se expresan de manera concisa y breve.

- No debe tener una extensión superior a las dos páginas y preferiblemente una única página; si la información que se desea transmitir es mucho más densa y requiere mayor espacio, lo más indicado será preparar un informe tan pormenorizado como sea necesario, acompañándolo de una carta en la que se indicará el objeto del informe y los principales conceptos.

- Si la carta tiene más de una página, se indicará en el margen inferior derecho $(1 / 2,2 / 2)$. La segunda deberá estar perfectamente identificada, aunque no es necesario que el impreso contenga todos los datos de la entidad, es suficiente con el logotipo.

- Mantiene la forma inicial de saludo así como las fórmulas de cortesía de despedida pese a que ambas se suprimieron expresamente en la Orden de 7 de julio de 1986 (BOE n. 174, de 22 de julio de 1986).

- Informaciones adicionales: el elemento postdata (P.D.) sirve para consignar una información breve a pie de página y después de la suscripción.

\section{Diferencias entre carta y oficio}

- La fórmula inicial de saludo en la carta es más amistoso.

- Disposición del contenido básicamente igual aunque el oficio siempre lleva membrete y deja amplio margen a la izquierda para notas.

- Tono de la carta más personalizado y cordial.

- La carta lleva fórmulas de despedida que el oficio no recoge.

- El pie de los documentos es distinto: el oficio lleva la dirección con indicación del puesto, etc., mientras que la carta no lleva pie de dirección.

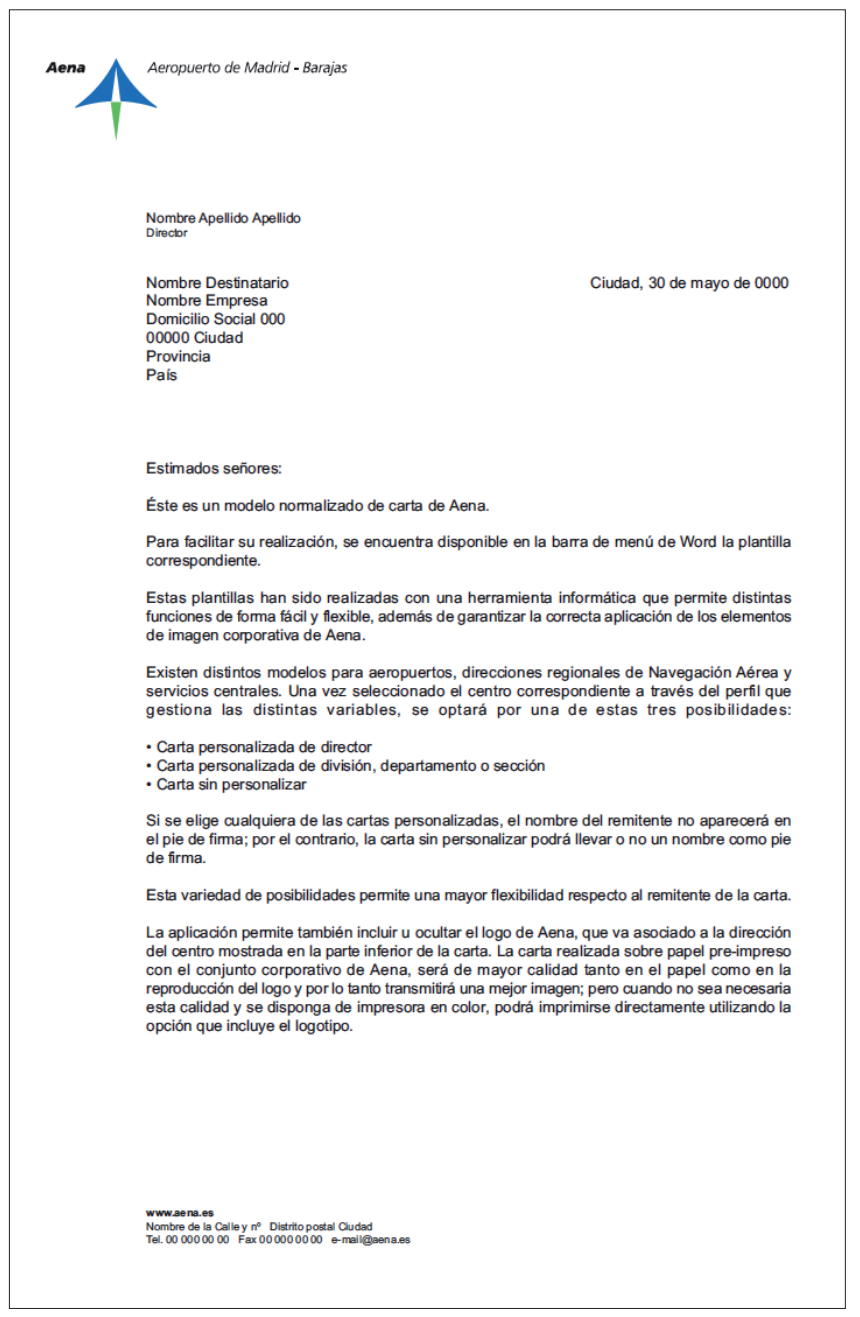

Figura 3. Modelo de carta. AENA. Manual de imagen corporativa

\section{Conclusión}

Este trabajo es una aproximación al tratamiento de los documentos de transmisión en los Manuales de identidad corporativa. En este momento en el que las tecnologías nos llevan a la administración electrónica y al acercamiento de la administración al ciudadano, diplomatistas y archiveros pueden y deben participar en la racionalización administrativa. Sin duda las tecnologías proporcionan gran inmediatez pero pueden adolecer de cierta ligereza en el diseño de los documentos administrativos, como el caso que se ha revisado y que se refiere a los documentos que vehiculan acuerdos y resoluciones desde la administración hasta sus administrados. 


\section{Notas}

1. La imagen promocional se utilizará como elemento de identificación y difusión de todas aquellas actividades, programas o medidas que se caractericen por su uso o impulso de la aplicación de soluciones tecnológicas a la gestión pública y, en particular, a las relaciones de los ciudadanos con la AGE y sus organismos públicos. Orden MAP/959/2003, de 11 de abril, por la que se aprueba la imagen promocional de las actividades de administración electrónica y se establecen criterios para su utilización. Art. 2.

2. La Junta de Andalucía expone en la presentación de su manual que "era el momento idóneo para plantearse una nueva imagen corporativa de la Junta, que imprima un sello de mayor vitalidad, singularidad y homogeneidad a la comunicación global de ésta, más acorde con los tiempos actuales. Así en la nueva imagen de la Junta de Andalucía, al mismo tiempo que se mantienen los caracteres y elementos básicos de la identidad corporativa, con su imprescindible puesta al día, se incorpora una nueva marca o logotipo para identificación de la Junta... simbología que, hundiendo sus raíces en los atributos que le son propios, los dota de un mayor dinamismo y actualidad".

3. La marca corporativa es la unión del escudo y del logotipo corporativos, formando un conjunto único e inseparable con sus correspondientes colores y tipografía. Las proporciones entre ellos no se deben alterar. $Y$ pueden tener varias configuraciones: horizontal, centrada y lateral. Puede usarse en color o monocolor, dependiendo del uso y del soporte en que vaya a ser utilizada. La marca tendrá que estar dotada de su zona de protección, es decir un espacio circundante que no debe ser invadido por ningún elemento gráfico (excepto el nombre de los departamentos, que junto con la marca configuran un conjunto) para permitir su óptima percepción. El conjunto de signos que simbolizan e identifican una institución son el logotipo, el símbolo, la denominación, la tipografía y los colores.

4. Además de la introducción se incluyen los siguientes capítulos: Elementos básicos de la imagen institucional, Normativa para material impreso, Integración de los signos básicos de la AGE y de los organismos dependientes, Normativa para publicaciones, Normativa para publicidad y promoción, Normativa de señalización exterior e interior, Normativa de la imagen de la Administración a través de elementos telemáticos, Regulación de la utilización de los elementos Institucionales, Normativa de identificación en actividades, publicaciones, obras o servicios de titularidad no estatal financiadas con fondos del Estado.

5. El manual de la AGE entiende que los impresos o documentos de la Administración tienen una especial importancia por que constituyen el principal instrumento de comunicación, ya sea personal, protocolaria o administrativa. Por eso intenta normalizar los soportes. En ese sentido se ocupa, en primer lugar, de la carta pero únicamente como "papel de carta" (2.4), no del resto de los documentos de comunicación; mientras que, más adelante, incluye otro apartado de papelería general en el que se ocupa del papel de trabajo, papel de oficio y papel de oficio con destinatario en ventana y nota interior (2.20 a 2.24). Por el contrario, se habla de modelo normalizado de solicitud en el 2.25. Así pues los documentos de comunicación se tratan de papelería general, pero no la carta ni tarjetas.

6. La diplomática es la ciencia que estudia los diplomas (documentos expedidos por alguna autoridad) y otros documentos teniendo en cuenta el soporte, escritura, lenguaje, formulismo y demás elementos integrantes para formar juicio de su autenticidad e interpretarlos debidamente.

7. Escatocolo, del griego escato = último, y kolo = goma, pega.

8. Real decreto $1465 / 1999$, de 17 de septiembre, por el que se establecen criterios de imagen institucional y se regula la producción documental y el material impreso de la AGE. Artículo 2: Imagen institucional.

"1.- La imagen institucional se fundamenta en la utilización, en todas las expresiones y comunicaciones, del escudo de España con las características establecidas en la Ley 33/1981, de 5 de octubre, y en el Real decreto 2964/1981, de 18 de diciembre, por el que se regula el modelo oficial del escudo de España, junto a la denominación del correspondiente departamento ministerial.

2.-La utilización del escudo de España junto a la denominación del correspondiente departamento será obligatoria de acuerdo con los formatos, diseños y supuestos de uso previstos en el presente Real decreto y en el manual de imagen institucional que se apruebe en aplicación del mismo".

9. Siempre que su rango sea igual o superior a subdirección general o equivalente, salvo excepciones justificadas, en castellano y en otras lenguas oficiales para el caso de la AGE.

10. Antiguo Régimen es el término que los revolucionarios franceses utilizaban para designar peyorativamente al sistema de gobierno anterior a la Revolución francesa de 1789 (la monarquía absoluta de Luis XVI), y que se aplicó también al resto de las monarquías europeas cuyo régimen era similar a aquél. El término opuesto a este fue el de Nuevo Régimen (en España, Régimen Liberal).

También puede aplicarse como equivalente a Edad Moderna, época con la que prácticamente coincidiría. Fuente: Wikipedia.

11. Los manuales de identidad corporativa son insistentes sin excepción en el tamaño del título, aunque en vez de "nota interior", algunos la denominan "comunicación interior" o "comunicación interna".

\section{Bibliografía}

Blanco-de-Tella, Luis. "Reflexiones sobre el lenguaje administrativo". Documentación administrativa. 1968, n. 122, pp. 73-88.

Fernández-Souto, Ana-Belén. La imagen corporativa en los ecosistemas comunicativos locales.

http://webs.uvigo.es/abfsouto/IDENTIDAD\%20CORPORA TIVA.

García-Rodríguez, Antonio. Diplomática del documento administrativo actual: tradición e innovación. Carmona: S\&C, 2001. Col. Biblioteca archivística, 8. ISBN: 97884923 91553. 


\section{MiBjb]joteca}

Actualidad bibliotecaria

Fotografía momentos de lectura

(0)inion

Recomendaciones de lectura Escolares

\section{Rúblicas}

Públicas Recursos Universitarias

Con pasado

Cartas a Mi B Bibliotecarios
Con futuro

Noticias

Gestión documental

www.mibiblioteca.org 